\title{
The laboratory investigation of vaginal discharge
}

\author{
Karen F Macsween, Geoffrey L Ridgway
}

The female genital tract has a complex microbial flora which varies with site, age of the patient, and hormonal background. Likewise, the quality and quantity of cervical and vaginal secretions vary with many factors including age, phase of the menstrual cycle, use of oral contraceptive, pregnancy, and presence of an intrauterine contraceptive device. Vaginal discharge may arise from the vagina, cervix, or upper genital tract. There are many noninfective causes of vaginal discharge; however, it is the role of the diagnostic microbiology laboratory to determine the presence of recognised microbial pathogens and disturbances of the normal flora.

The normal flora of the vagina changes according to circulating oestrogen levels. When oestrogen is present, the vaginal epithelium contains glycogen which favours colonisation by lactobacilli and other acid tolerant bacteria, which metabolise glycogen to lactic acid. This results in a $\mathrm{pH}$ of 4.5 or less. Other bacteria commonly present in large numbers include anaerobic streptococci, diphtheroids, coagulase negative staphylococci, and $\alpha$ haemolytic streptococci. Other common commensals which can act as pathogens include Candida spp, Staphylococcus aureus, $\beta$ haemolytic streptococci including Str agalactiae, and Actinomyces spp. In bacterial vaginosis the concentration of Gardnerella vaginalis, Mobiluncus spp, anaerobic gram negative rods (for example, Bacteroides spp, Prevotella spp, and Porphyromonas spp) and Mycoplasma hominis increases, compared with the lactobacilli.

The vaginal secretions of prepubertal children and postmenopausal women are more alkaline and contain a varied bacterial flora dominated by coagulase negative staphylococci, diphtheroids, $\alpha$ haemolytic streptococci, lactobacilli, non-haemolytic streptococci, anaerobic

Department of Clinical Microbiology,

University College

Hospital, London

WC1E 6DB, UK

K F Macsween

G L Ridgway

Correspondence to: Dr G L Ridgway.

Accepted for publication 13 May 1998 likely to be contaminated with perineal/faecal flora. High vaginal swabs (HVS) should be placed in transport medium to prevent drying (important for $M$ hominis) and to allow the survival of anaerobes. For the identification of Neisseria gonorrhoeae and Chlamydia trachomatis endocervical swabs are required. Failure to isolate $N$ gonorrhoeae from an HVS does not exclude gonorrhoea. There is evidence that vaginal swabs may be suitable for the detection of $C$ trachomatis using molecular techniques (for example, PCR or LCR), but further work is needed before this can be recommended.

To collect an endocervical swab the cervix should be gently wiped with a sterile swab before a further cotton swab is inserted into the cervix and rotated $360^{\circ}$. The addition of charcoal to the transport medium (Bibby Sterilin, Stone, Staffordshire, UK) improves the survival of the gonococcus but, ideally, cervical smears should be prepared and warmed media inoculated at the bedside. Rectal, urethral, and pharyngeal swabs may also be taken for culture of $N$ gonorrhoeae if indicated.

Harvesting of endocervical cells from the squamocolumnar junction is required for chlamydial culture, detection of chlamydial antigen, or chlamydial DNA by PCR or LCR. After wiping the cervix with sterile gauze or a swab, a sterile swab (not charcoal impregnated) should be inserted into the cervical canal, rotated, and then wiped across the surface of the cervix if ectropion is present.

Swabs for chlamydial cell culture which cannot be processed within 24 hours must be stored at $-70^{\circ} \mathrm{C}$, and not at $-20^{\circ} \mathrm{C}$. Endocervical swabs for specific immunofluorescence are spread directly onto a glass slide and air dried.

Intrauterine devices for culture should be submitted dry, in a sterile container.

\section{Assessment of specimens}

Processing of the specimens in the laboratory depends on the specimen type, referral source, age of the patient, and the clinical details given. All too often the latter are illegible, inadequate, or abbreviated. Specimens from cases of assault or suspected sexual abuse must have a laboratory chain of evidence form completed, documenting the passage of the specimen from the clinic to the laboratory.

It is convenient to divide specimens into those requiring a full culture and those requiring a screening culture. A screening culture will 
Table 1 Indications for full culture

\begin{tabular}{ll}
\hline $\begin{array}{l}\text { Postoperative } \\
\text { Pregnancy }\end{array}$ & $\begin{array}{l}\text { Following termination of pregnancy, hysterectomy } \\
\text { Premature labour, prolonged rupture of membranes, } \\
\text { spontaneous rupture of membranes, antepartum } \\
\text { haemorrhage, threatened abortion. Shirodkar suture in situ }\end{array}$ \\
$\begin{array}{l}\text { Postnatal discharge or fever } \\
\text { Pelvic inflammatory disease }\end{array}$ & $\begin{array}{l}\text { Salpingitis, endometritis, endometriosis, intrauterine device } \\
\text { in situ } \\
\text { Full culture should always be undertaken }\end{array}$ \\
\hline
\end{tabular}

include selective plates for $N$ gonorrhoeae, Candida spp, and $\beta$ haemolytic streptococci; and microscopy for Trichomonas vaginalis and bacterial vaginosis. Culture of vaginal swabs in cases of trichomonal infection and bacterial vaginosis does not yield significantly more information than microscopy alone. Full culture is indicated in the clinical situations shown in table 1 .

\section{Microscopy}

In those specimens designated to receive screening culture only, a wet preparation is undertaken, unless the clinical details state "vaginosis" or "Gardnerella," when a Gram stain and wet preparation are made. Specimens receiving "full culture" are Gram stained routinely. When cervical and high vaginal
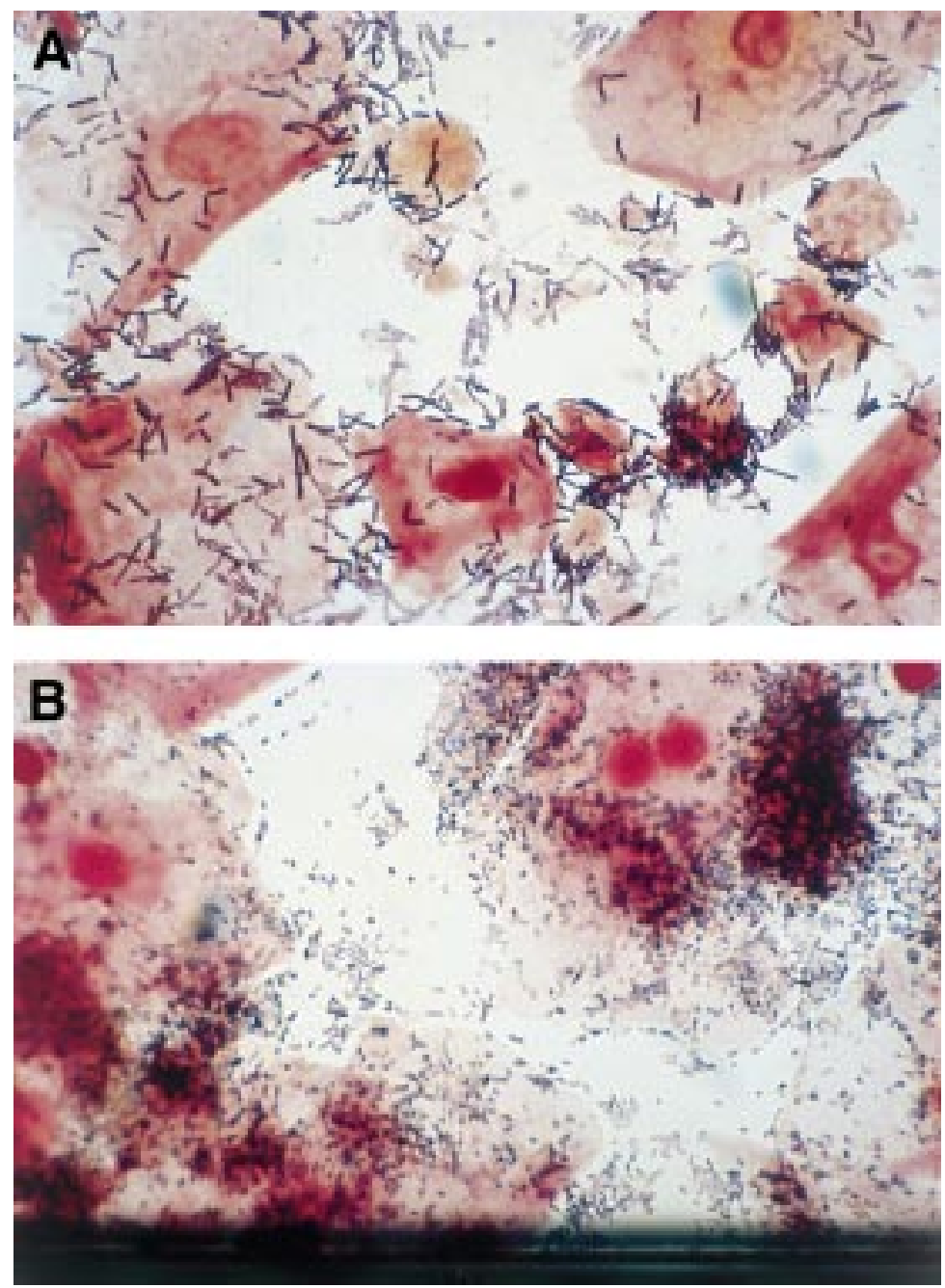

Figure 1 Normal lactobacillus predominant vaginal flora $(A)$ and typical Gram variable coccobacilli and clue cell of bacterial vaginosis $(B)$. (Original magnification $\times 1000$.) swabs are received, the HVS is used for wet preparation.

WET PREPARATIONS

Vaginal fluid is added to a drop of saline on a slide, and covered with a coverslip. Wet preparations are checked for the presence of $T$ vaginalis, yeast cells, pus cells, epithelial cells, and clue cells. Clue cells are vaginal epithelial cells covered with numerous, short coccobacilli. In addition lactobacilli will be absent or reduced in number when clue cells are present. If clue cells are seen on the wet preparation a confirmatory Gram stain is made. The relative numbers of epithelial and pus cells can be helpful. Culture for $T$ vaginalis will yield few additional positives.

\section{Bacterial vaginosis}

Bacterial vaginosis is a common cause of vaginal discharge in which there is disturbance of the normal vaginal flora without inflammation of the vagina. Figure 1A shows the normal lactobacilli predominant flora, and fig $1 \mathrm{~B}$ the typical appearance of Gram variable coccobacilli and clue cells in bacterial vaginosis. There is overgrowth of organisms normally present in small numbers, and a reduction or absence of lactobacillli. Bacterial vaginosis is diagnosed when three out of four of the following are present:

- abnormal, thin, homogeneous vaginal discharge;

- vaginal $\mathrm{pH}>4.5(\mathrm{NB}, \mathrm{pH}$ of cervical mucus is 7). The presence of blood, serum, or vaginal preparations may affect the $\mathrm{pH}$;

- positive amine test;

- presence of clue cells.

Vaginal $\mathrm{pH}$ should be measured in the clinic by applying narrow range $\mathrm{pH}$ papers to a drop of discharge on a glass slide. The amine test is then performed by adding a drop of $10 \%$ potassium hydroxide to the vaginal discharge. A positive test is signified by a transient fishy odour, caused by the liberation of aromatic amines. The presence of clue cells is the most sensitive and specific marker of bacterial vaginosis. Culture does not form the basis of a diagnosis of bacterial vaginosis. The routine culture of specimens for $G$ vaginalis should be discouraged. If pus cells are seen on microscopy, an additional diagnosis should be sought. The full significance of bacterial vaginosis is gradually unfolding and currently it is recognised as a risk factor in:

- preterm labour/late miscarriage;

- ascending infection of the female genital tract;

- endometritis following caesarean section;

- vaginal cuff cellulitis following abdominal hysterectomy;

- neonatal sepsis.

\section{Culture}

The procedure for handling specimens to receive a screening culture is shown in table 2 . For specimens receiving full culture, a Gram 
Table 2 Investigation of vaginal discharge: screening culture

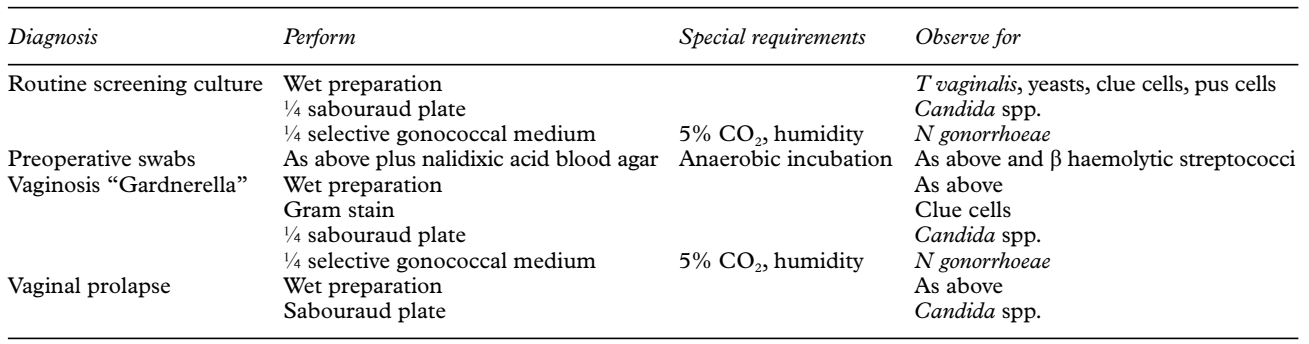

Table 3 Investigation of vaginal discharge: full culture

\begin{tabular}{|c|c|c|}
\hline Diagnostic group & Possible pathogens & Suggested media and special requirements \\
\hline Postoperative & $\begin{array}{l}\text { Staph aureus } \\
\text { Listeria monocytogenes } \\
\text { Str pyogenes }\end{array}$ & Blood agar, $5 \% \mathrm{CO}_{2}$ \\
\hline Postpartum & Str agalactiae & Neomycin blood agar, metronidazole disc \\
\hline Pregnancy & $\mathrm{Cl}$ perfringens & Anaerobic incubation \\
\hline Pelvic inflammatory disease & $\begin{array}{l}\text { Bacteroides spp } \\
\text { coliforms } \\
N \text { gonorrhoeae } \\
\text { Mycoplasma hominis }\end{array}$ & $\begin{array}{l}\text { MacConkey } \\
1 / 4 \text { selective gonococcal medium in } 5 \% \mathrm{CO}_{2} \\
\text { Mycoplasma (not required for elderly and } \\
\text { post-hysterectomy patients), incubate } \\
\text { anaerobically } 72 \text { hours }\end{array}$ \\
\hline IUCD & As above plus Actinomyces spp & $\begin{array}{l}\text { Actinomyces selective medium incubated } \\
\text { anaerobically up to } 12 \text { days }\end{array}$ \\
\hline Children & $\begin{array}{l}\text { Str pyogenes, H influenzae, Str pneumoniae } \\
\text { Candida spp } \\
N \text { gonorrhoeae }\end{array}$ & $\begin{array}{l}\text { Chocolate agar } \\
\text { Sabouraud medium } \\
\text { Selective gonococcal medium }\end{array}$ \\
\hline
\end{tabular}

stain is prepared and plates are inoculated as shown in table 3.

\section{NEISSERIA GONORRHOEAE}

A purulent endocervical discharge is only apparent in 10-20\% of infected women. Microscopy and culture remain the basis for diagnosis of gonorrhoea. In women with gonorrhoea, Gram stains of endocervical smears are more difficult to interpret owing to a greater amount of debris, and are less sensitive than smears from the male urethra. Culture on a selective medium is essential for cervical specimens to prevent overgrowth of the plate with normal flora (for example, VCNT blood agar, GC base; Difco Laboratories, West Molesey, Surrey, UK). The agar should be fresh, and specimens should be incubated in a moist atmosphere containing $5-10 \% \mathrm{CO}_{2}$ for 24 to 48 hours. Colonies of $\mathrm{N}$ gonorrhoeae are 0.5 to $2 \mathrm{~mm}$ in diameter, shiny and grey. Suspect colonies which are oxidase positive should be Gram stained. Gram negative diplococci should be confirmed as gonococci by sugar utilisation tests or by a coagglutination test, for example Phadebact ${ }^{\circledR}$ (Launch Diagnostics, Longfield, Kent, UK).

\section{Sensitivity testing of $N$ gonorrhoeae}

Resistance to penicillin is common. Tetracycline resistance is increasing, with establishment of the TETm plasmid. Ciprofloxacin resistant strains are emerging from Southeast Asia. Disc testing should be performed using penicillin $0.25 \mathrm{U}$, penicillin $1 \mathrm{U}$, cefuroxime 30 $\mu \mathrm{g}$, tetracycline $10 \mu \mathrm{g}$, spectinomycin $10 \mu \mathrm{g}$, and nalidixic acid $0.03 \mu \mathrm{g}$. If there is no zone against the nalidixic acid disc, the test is repeated, including a ciprofloxacin $1 \mu \mathrm{g}$ disc in addition (low volume $(0.1 \mu \mathrm{g})$ ciprofloxacin discs are no longer readily available).
$\beta$-Lactamase production can most easily be assessed by the chromogenic cephalosporin method. One drop of nitrocefin solution is placed on a piece of filter paper. One colony is rubbed into the nitrocefin impregnated paper. $\beta$-Lactamase activity is indicated by a rapid colour change from yellow to red in the inoculated area. Control organisms (positive and negative) should also be tested.

\section{CHLAMYDIA TRACHOMATIS}

Chlamydiae are incapable of growth in a cell-free medium. Diagnosis depends on cell culture, antigen detection, or detection of chlamydial DNA. Serology is not helpful in diagnosing genital infection in adults.

Description of the various methods available for non-culture diagnosis of chlamydial infection is beyond the scope of this broadsheet. The subject has recently been reviewed by Black. ${ }^{1}$

MYCOPLASMAS AND UREAPLASMAS

The genital mycoplasmas, Mycoplasma hominis and Ureaplasma urealyticum, are widely prevalent in sexually active women. $M$ hominis has been associated with pelvic inflammatory disease, although its role as a prime pathogen is disputed. It is an occasional cause of postpartum pyrexia. A pathogenic role for $U$ urealyticum in women is even more difficult to define, but the organism is associated with respiratory problems in low birthweight or premature infants. $M$ genitalium may be involved in some cases of pelvic inflammatory disease but it is extremely difficult to isolate. Routine culture for these organisms probably cannot be justified by most diagnostic laboratories, but a brief description is given here to aid those who attempt to do so in the situations described 
above. $M$ hominis and $U$ urealyticum may be isolated using a selective medium (for example, Oxoid GMP mycoplasma medium) which is incubated in a moist atmosphere for 72 hours. This can be incubated microaerobically or anaerobically, but in practice a moist environment is easier to maintain anaerobically. Growth is detected by examining the agar plate directly under a plate microscope. $M$ hominis colonies appear as "fried eggs" 50 to $500 \mu \mathrm{m}$ in size, while $U$ urealyticum colonies appear smaller and denser and are 50 to $100 \mu \mathrm{m}$ in size. Culture of $U$ urealyticum yields brown colonies in the presence of manganous salts when viewed by transmitted light.

\section{ACTINOMYCOSIS}

Actinomyces israelii may cause infection in association with an intrauterine contraceptive device (IUCD). The IUCD should be inspected for sulphur granules using a plate microscope. If present a granule should be crushed between two microscope slides, heat fixed, and Gram stained to look for branching Gram positive filaments. In the absence of diagnostic sulphur granules the IUCD is used to inoculate selective agar (brain-heart infusion agar with defibrinated horse blood, nalidixic acid, and metronidazole) and is then itself incubated in fastidious anaerobic broth (FAB; Bioconnections, Bardsey, Yorkshire, UK) for five days. The broth is then subcultured onto another of the selective plates. Both sets of plates should be incubated anaerobically and examined at 5, 7, 9, and 12 days. Thick plates $(>4 \mathrm{~mm}$ ) should be prepared to minimise drying during the prolonged incubation.

\section{Special situations}

CHILDREN

Vulvovaginitis is a common condition of prepubertal girls and presents with dysuria, soreness, or itching. The most common bacterial causes are Str pyogenes and non-capsulate Haemophilus influenzae. ${ }^{2}$ Other causes include candida, Str pneumoniae, Staph aureus, other $\beta$ haemolytic streptococci, $N$ gonorrhoeae, and $C$ trachomatis. Non-bacterial causes to consider are retained foreign body and threadworm infection. In children vaginal swabs only will be taken and these should always be submitted for full culture. The prepubertal vaginal epithelium can be infected with $N$ gonorrhoeae and $C$ trachomatis and this specimen is adequate for diagnosis. If a chlamydial infection is a possibility in a child, cell culture for $C$ trachomatis should be undertaken at a centre experienced in this technique. The report of Royal College of Physicians on child sexual abuse confirms the legal requirement for cell culture, pointing out that immunofluorescence and immunoassays have not been validated in prepubertal children. ${ }^{3}$ This report further states that, if a non-culture method is used, treatment should be delayed until the result is available, as any positive result should be confirmed by taking a further sample for cell culture. It is therefore highly desirable that the preferred samples are taken at initial consultation.

POSSIBLE LEGAL CASES

If specimens are taken from patients of any age where sexual assault or abuse is considered, or if the diagnosis of a sexually transmitted disease is considered in a child, a chain of evidence form should be initiated by the clinician who took the specimens. All persons thereafter who handle the specimen (including transport to the laboratory, subsequent cultures, and results) should document their involvement. Specimens for $C$ trachomatis from these cases require culture.

\section{Reporting of significant isolates}

Heavy growths of Staph aureus, $\beta$ haemolytic streptococci, and mixed anaerobes should be reported. Heavy growths of coliforms may be significant in certain circumstances, for example retained products of conception. Scanty or mixed growths of Staph aureus and nongroup-A $\beta$ haemolytic streptococci are not usually reported. An exception to this is Str agalactiae, which should be reported when isolated from an HVS taken around the time of childbirth because of its importance as a cause of neonatal sepsis.

1 Black CM. Current methods of laboratory diagnosis of Clin Microbiol Rev 1997;10:160-84.

2 Cox RA. Haemophilus influenzae an underrated cause of vulvovaginitis in young girls. $\mathcal{F}$ Clin Pathol 1997;50:765-8.

3 Royal College of Physicians. Physical signs of sexual abuse in children, 2nd ed. London: Royal College of Physicians, children, 2nd ed. London: Royal College of Physicians,
1997. (Appendix 4b gives advice on the collection of microbiological specimens.)

Further reading

Amsel R, Totten PA, Speigel CA, et al. Nonspecific vaginitis. Diagnostic criteria and microbial and epidemiologic associations. Am f Med 1983;74:14-22.

Ison CA. Antimicrobial agents and gonorrhoea: therapeutic choice, resistance, and susceptibility testing. Genitourinary Med 1996; 72:253-7.

Ridgway GL, Taylor-Robinson D. Current problems in microbiology. 1. Chlamydial infections: which laboratory test? $\mathcal{F}$ Clin Pathol 1991; 44:1-5.

Sobel JD. Vaginitis. N Engl f Med 1997; 337:1896-903.

Spiegel CA. Bacterial vaginosis. Clin Microbiol Rev 1991;4:485-502.

Stokes EJ, Ridgway GL, Wren MWD. Clinical microbiology, 7th ed: chapter 4, Specimens from sites with a normal flora; and chapter 12, Media preparation and other techniques. London: Edward Arnold, 1993. 